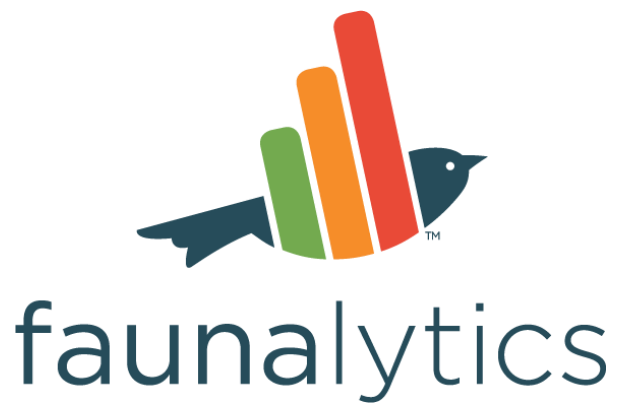

\title{
The People Who Support Animal Causes: Descriptive Results
}

February 2019

Author: Jo Anderson

Faunalytics 


\title{
Contents
}

(Click to go to page)

\author{
Background \\ Report Contents \\ Key Findings \\ Future Analyses \\ Sample And Method \\ PART ONE: DONOR CHARACTERISTICS \\ Basic Demographics \\ Potential Donors \\ Additional Demographics \\ Donor Activities And Habits \\ Volunteering And Working With Animals \\ Diet \\ Companion Animals \\ Animal-Related Hobbies \\ PART TWO: DONOR BEHAVIOR \\ Donation Amounts \\ Causes Supported \\ Specific Animal Causes Supported When "All Else Is Equal" \\ Most Important Charity \\ Reasons For Donating \\ Donation Methods \\ Other Methods Of Support \\ Conclusions \& Recommendations \\ Supplementary Materials
}




\section{faunalytics}

\section{Background}

This study was driven by a desire to increase the number and size of donations to animal causes. Our eventual goal is to conduct one or more experiments to directly test methods of increasing donations, but we first need a strong foundation of data about current donors and donation patterns. Surprisingly little is known about who donates to animal causes, how they donate, and why they donate to some causes but not others.

This study builds on data from Faunalytics' recent reanalysis of data collected by the Blackbaud Institute and Edge Research from donors to all charitable causes. The sample of animal-cause donors in that dataset was a small subset of the whole, and many animal advocacy organizations expressed strong interest in learning more about animal donors.

For the current study, we collected data from a much larger sample of animal-cause donors. These results provide details specific to the interests of animal advocacy and protection organizations.

\section{Report Contents}

The first half of the report describes donor characteristics: basic and additional demographics of people who donate to animal causes, diet, animal guardianship, and animal-related hobbies.

The second half covers donor behavior: how much animal-cause donors give, which causes they support-animal and otherwise, which charities are most important to them, how they prefer to donate, and more.

\section{Key Findings}

1. Most animal-cause donors give to companion animal charities, often exclusively. We were not surprised to find that $82 \%$ of respondents had given money to companion animal charities. In addition, two thirds of those donors had not given money to any other type of animal charity. Overall, $25 \%$ of donors had given money to charities for wildlife or endangered species, $17 \%$ to charities for a broad range of animals, and $12 \%$ to charities for farmed animals (including sanctuaries).

2. The overwhelming "preference" for companion animal charities may actually be about familiarity rather than preference. When presented with a range of charity options in a hypothetical donation scenario, the percentage of people who donated to companion animal charities was about the same (85\%), but the number of people who donated to other animal causes increased dramatically: $52 \%$ donated part of the money to charities for wildlife or endangered species; $49 \%$ to charities for a broad range of animals; $37 \%$ to marine animals; $29 \%$ to donkeys, horses, etc.; $28 \%$ to animals used in science; and $26 \%$ to farmed animals. This result suggests that the smaller proportion of donations to noncompanion animal charities can be partially explained by their lack of visibility rather than donors' lack of motivation. When presented with the option to expand their donations, many people took it. 


\section{faunalytics}

3. The most promising demographics to target for new donations are people aged $\mathbf{5 5}$ and up and people with incomes of at least $\$ 50,000$. These groups had the largest proportions of "potential donors"- people who have donated money in the past year (and therefore can afford to) but have not supported an animal charity. In particular, it is important to remember that older demographics should not be ignored when it comes to fund-raising because, as a movement, we tend to focus our efforts on younger people.

4. The typical donor gave $\$ 100$ to animal charities in the past 12 months, and this represented $30 \%$ of their total donations. Donations ranged from $\$ 1$ to $\$ 10,000$, and from less than $1 \%$ to $100 \%$ of their total donations. As is often the case, a small percentage of major donors contributed a large proportion of the total dollars to animal causes.

5. People were much more likely to describe their reasons for donating in terms of animal protection or welfare than animal rights. Describing animals as "vulnerable" or "innocent" was common, while describing them as deserving of equal treatment or respect was not.

6. One in three people who donates to animal causes names an animal charity as the most important charity to them personally. Everyone was asked which animal charity was most important to them. Most people (79\%) named a companion animal charity. Another $9 \%$ named a charity for wildlife or endangered species conservation, and $4 \%$ named charities for a broad range of animals. The remaining causes were named by $1 \%$ of respondents or fewer.

7. Animal-cause donors care about a variety of issues, human and animal. Only $9 \%$ of respondents had donated exclusively to animal causes. The vast majority spread their donations around. Among animal-cause donors, the most supported human causes were for vulnerable populations: local social service organizations (e.g., food banks), children's charities, and emergency relief efforts. Speculatively, highlighting animals' vulnerability to human exploitation and abuse might increase the size or frequency of donations from existing donors.

8. After online donations, which were made by $39 \%$ of the sample, the next most common donation methods were mail $(25 \%)$ and in-person donations at a charity's location (25\%). Given the increasing emphasis on online donations, it is important to note the majority of animal-cause donors who had not used that method in the past year. In addition, many respondents indicated that they prefer less-common donation options like adding a donation to their bill at a store.

9. People who donate to animal causes are more likely to be vegan or vegetarian, to live with companion animals, and to go fishing regularly than the general population. Although some animal-cause donors live more animal-friendly lives, many do not. In some ways, such as fishing, they are actually less animal-friendly on average. 


\section{-1 faunalytics}

\section{Future Analyses}

This report covers the weighted descriptive results and qualitative findings from this large dataset. Upcoming releases will include:

1. A report that provides more detail on high-impact donors, including people who donate large amounts and people who donate to non-companion animal causes. Additional data in these areas has a lot of potential benefit for animals.

2. We also plan to look more deeply at how donor characteristics relate to attitudes, preferences, and behavior. For example, are there characteristics that differentiate donors who do more (volunteering, other support) from those who don't?

\section{Sample And Method}

For this study, we recruited a representative U.S. sample through Research Now SSI. All participants completed a short screening questionnaire that included demographic questions and two attention checks. Our goal with this screener was to identify at least 1,000 respondents who had donated to an animal cause within the past twelve months. Respondents who met this criterion completed the remainder of the survey.

After data cleaning, our final sample for analysis was 1,036 animal donors from a full sample of 8,838 . With the data weighted to improve estimates, we found that $12 \%$ of the U.S. population has given money to an animal cause in the past twelve months. (This is on par with the $13 \%$ estimated by the 2017 Faunalytics Animal Tracker.)

The overall margin of error for our estimates is $\pm 3.0 \%$ with $95 \%$ confidence. In other words, for any percentage of the full sample reported below, the percentage in the entire U.S. population will be within $3 \%$ of our estimate nineteen times out of twenty. In a few cases where we analyzed a subsample, or where more specificity is helpful, we provide the margin of error (confidence interval) for individual estimates.

Methodological notes: The data-cleaning procedure is described in the Supplementary Materials. All quantitative analyses are weighted. Qualitative analyses of open-ended data are unweighted. 


\section{PART ONE: DONOR CHARACTERISTICS}

\section{Basic Demographic Characteristics Of Animal-Cause Donors}

Table 1 shows the standard demographic characteristics of the U.S. population and of our sample of animal donors, so that the differences are evident. We weighted the full sample of respondents ( $n=8,838)$ to population values. The demographics of our sample of animal-cause donors are therefore representative of what would be found in the U.S. population.

In Table 1 (p. 7), there is an asterisk $\left(^{*}\right)$ next to percentages that are estimated to be significantly different from the population based on their margin of error. For example, the asterisk in the first line of data indicates that there are significantly fewer males aged 18 to 24 in the population of animal-cause donors than in the general population.

Overall, people who donate to animal causes appear to be older, more often female, more often White and non-Hispanic, less often from the South, and higher-income than the general U.S. population. 
Table 1. Demographic Characteristics Of Animal-Cause Donors Versus U.S. Population

\begin{tabular}{|c|c|c|}
\hline Characteristic & $\begin{array}{r}\text { Animal-Cause Donors } \\
\text { (Weighted) }\end{array}$ & U.S. Population \\
\hline Overall Male (\%) & $42.7 *$ & 48.7 \\
\hline Male 18-24 & $3.5^{\star}$ & 6.3 \\
\hline Male 25-34 & $4.9 *$ & 9.1 \\
\hline Male 35-44 & 7.1 & 8.1 \\
\hline Male 45-54 & 9.0 & 8.5 \\
\hline Male 55-64 & 9.8 & 8.0 \\
\hline Male $65+$ & 9.0 & 8.7 \\
\hline Overall Female (\%) & $56.6 *$ & 51.3 \\
\hline Female 18-24 & 4.7 & 6.0 \\
\hline Female 25-34 & $6.2^{\star}$ & 8.8 \\
\hline Female $35-44$ & $6.5^{\star}$ & 8.2 \\
\hline Female 45-54 & 10.2 & 8.7 \\
\hline Female 55-64 & $13.1 *$ & 8.6 \\
\hline Female 65+ & $15.9 *$ & 11.0 \\
\hline \multicolumn{3}{|l|}{ Race (\%) } \\
\hline White & $86.5^{\star}$ & 72.4 \\
\hline Black or African-American & $3.0 *$ & 12.6 \\
\hline Asian & $3.1 *$ & 4.8 \\
\hline Other or Multi-Racial & $7.4 *$ & 10.2 \\
\hline \multicolumn{3}{|l|}{ Ethnicity (\%) } \\
\hline Hispanic & $8.2^{*}$ & 15.7 \\
\hline \multicolumn{3}{|l|}{ Region (\%) } \\
\hline Northeast & 20.7 & 18.7 \\
\hline Midwest & 22.7 & 22.5 \\
\hline South & $32.8 *$ & 35.9 \\
\hline West & 23.9 & 22.9 \\
\hline \multicolumn{3}{|l|}{ Income (\%) } \\
\hline Less than $\$ 25,000$ & $14.5^{\star}$ & 28.3 \\
\hline$\$ 25,000$ to $\$ 49,999$ & 29.5 & 28.3 \\
\hline$\$ 50,000$ to $\$ 74,999$ & $22.5 *$ & 19.3 \\
\hline$\$ 75,000$ to $\$ 99,999$ & 15.0 * & 10.7 \\
\hline$\$ 100,000$ or more & $18.5^{*}$ & 13.4 \\
\hline
\end{tabular}

Notes. An asterisk $\left(^{*}\right)$ indicates that the U.S. population value falls outside the confidence interval for the animalcause donor estimate.

$0.7 \%$ (weighted) of the donor sample self-identified as a gender other than male or female. 


\section{-1 faunalytics}

\section{Potential Donors}

Knowing who currently donates to animal causes is useful, but not perfect. This kind of demographic analysis can cause a self-fulfilling prophecy. Continuing to reach out to typical supporters is a good way to maintain current donation levels, but speaking to the interests of other communities may bring in new supporters from a broader range of backgrounds.

Where should we look for new supporters? Not all communities or demographics are equally able to provide monetary support to a cause. In order to address this question, we looked for people who indicated in our screener that they had donated money in the past 12 months, but not to any animal cause. This suggests that they have the means to donate, but do not direct those donations to animals. Better donation appeals toward these groups have the potential to broaden our support.

The results are shown in Table 2 below (p. 9). First, note that every demographic group has more potential donors than current donors-many people of all demographics support human charities over animal charities.

However, the demographic groups with the largest proportions of potential donors are:

- Males aged 65 and older (49\% are potential donors);

- Females aged 65 and older (45\% are potential donors);

- People with incomes of $\$ 100,000$ or more (43\% are potential donors);

- Males aged 55-64 (41\% are potential donors);

- People with incomes between $\$ 50,000$ and $\$ 99,999$ (37\% to 39\% are potential donors); and

- Females aged 55-64 (35\% are potential donors).

In short, many older people and wealthier people could donate to animals but are not doing so currently. If campaigns could successfully appeal to one or more of these demographics, it could dramatically increase the number of donors to animal causes.

This is important to bear in mind for older people in particular, as the animal protection movement tends to focus on younger people for behavioral change. 
Table 2. Current, Potential, and Non-Donors By Demographic Group

\begin{tabular}{|c|c|c|c|}
\hline Characteristic & Potential Donors & Current Donors & Non-Donors \\
\hline Overall Male (\%) & 31 & 10 & 59 \\
\hline Male 18-24 & 12 & 7 & 82 \\
\hline Male 25-34 & 21 & 6 & 73 \\
\hline Male 35-44 & 27 & 10 & 63 \\
\hline Male 45-54 & 29 & 12 & 58 \\
\hline Male 55-64 & 41 & 14 & 45 \\
\hline Male 65+ & 49 & 12 & 39 \\
\hline Overall Female (\%) & 30 & 13 & 58 \\
\hline Female 18-24 & 15 & 9 & 76 \\
\hline Female 25-34 & 21 & 8 & 71 \\
\hline Female 35-44 & 26 & 9 & 65 \\
\hline Female 45-54 & 27 & 14 & 59 \\
\hline Female 55-64 & 35 & 18 & 47 \\
\hline Female 65+ & 45 & 17 & 38 \\
\hline \multicolumn{4}{|l|}{ Race (\%) } \\
\hline White & 32 & 14 & 54 \\
\hline Black or African-American & 27 & 3 & 71 \\
\hline Asian & 29 & 8 & 63 \\
\hline Other or Multi-Racial & 24 & 8 & 68 \\
\hline \multicolumn{4}{|l|}{ Ethnicity (\%) } \\
\hline Hispanic & 22 & 9 & 70 \\
\hline \multicolumn{4}{|l|}{ Region (\%) } \\
\hline Northeast & 31 & 13 & 57 \\
\hline Midwest & 32 & 12 & 56 \\
\hline South & 29 & 11 & 61 \\
\hline West & 29 & 12 & 59 \\
\hline \multicolumn{4}{|l|}{ Income (\%) } \\
\hline Less than $\$ 25,000$ & 18 & 6 & 76 \\
\hline$\$ 25,000$ to $\$ 49,999$ & 28 & 12 & 60 \\
\hline$\$ 50,000$ to $\$ 74,999$ & 37 & 13 & 49 \\
\hline$\$ 75,000$ to $\$ 99,999$ & 39 & 16 & 45 \\
\hline$\$ 100,000$ or more & 43 & 16 & 41 \\
\hline
\end{tabular}

Notes. "Non-donors" indicates people who did not give any money to charity in the past 12 months. "Potential donors" indicates people who gave money to charity in the past 12 months, but not to animal causes (i.e., they are able to donate but have not). "Current donors" indicates people who gave money to animal causes in the past 12 months.

Rows may not add up to exactly $100 \%$ due to rounding. 


\section{Additional Demographic Characteristics Of Animal-Cause Donors}

We also collected data on several less common demographic characteristics. Whenever possible, we compared the results with the general population. Table 3 (p. 11) shows the questions for which we can compare the data collected from animal-cause donors with the general population.

Looking at the table suggests that, compared with the general population, people who donate to animal causes tend to be more educated and more liberal. In addition, it appears that fewer animal-cause donors are Protestant than in the general population, that they attend religious services less frequently, and that they are more likely to speak English at home. Marital status figures look similar-animal-cause donors may be more likely to be divorced (without being remarried) than the general population, but we can't tell whether the difference is significant.

Methodological note: We can't analyze these data to see whether animal-cause donors differ significantly from the general population because the data were collected with different methods and have unknown margins of error. 


\title{
Table 3. Animal-Cause Donors Versus General Population
}

\author{
Characteristic
}

Animal-Cause

Donors

(Weighted)

General Population Sample

(Weighted)

\begin{tabular}{|c|c|c|}
\hline \multicolumn{3}{|l|}{ Education (\%) } \\
\hline Less than high school graduate & $<1$ & 11 \\
\hline High school graduate & 16 & 29 \\
\hline Some college, no degree & 27 & 19 \\
\hline Associate degree & 14 & 10 \\
\hline Bachelor's degree & 26 & 20 \\
\hline Master's degree & 12 & 8 \\
\hline Professional or doctorate degree & 4 & 3 \\
\hline \multicolumn{3}{|l|}{ Political Orientation (\%) } \\
\hline Conservative & 29 & 35 \\
\hline Moderate & 37 & 35 \\
\hline Liberal & 34 & 26 \\
\hline \multicolumn{3}{|l|}{ Religion (\%) } \\
\hline Protestant & 23 & 40 \\
\hline Catholic & 25 & 23 \\
\hline Mormon & 1 & 2 \\
\hline Other Christian & 13 & 10 \\
\hline Jewish & 4 & 2 \\
\hline Other religion & 7 & 5 \\
\hline No religion & 27 & 21 \\
\hline \multicolumn{3}{|l|}{ Religious Attendance (\%) } \\
\hline At least once a week & 19 & 36 \\
\hline $\begin{array}{l}\text { Once or twice a month/several times in the } \\
\text { past year }\end{array}$ & 22 & 33 \\
\hline Once or twice in the past year/Never & 58 & 30 \\
\hline Don't know & 2 & 1 \\
\hline \multicolumn{3}{|l|}{ Language at home $(\%)$} \\
\hline English & 99 & 79 \\
\hline Spanish & 1 & 13 \\
\hline Another language & $<1$ & 8 \\
\hline \multicolumn{3}{|l|}{ Marital status (\%) } \\
\hline Married or domestic partnership & 54 & 52 \\
\hline Never married & 28 & 32 \\
\hline Divorced & 12 & 6 \\
\hline Widowed & 6 & 10 \\
\hline
\end{tabular}

Source of population data about education, language used at home and marital status:

U.S. Census Bureau.

Source of population data about political orientation and religion: Gallup.

Adjusted to remove 'no answer.'

Source of population data about religious attendance: Pew Research Center.

Category wording is slightly different. 
Additional demographic information for animal-cause donors is shown in the figure below. These are questions for which we do not have comparable figures from the general population, with the exception of retirees. A minority live in rural areas, a large proportion have no children, and most are employed or retired. The percentage of retirees among animal-cause donors (30\%) is substantially higher than in the general population (15\%; Bureau of Labor Statistics).

Figure 1. Additional Demographics For Animal-Cause Donors Region Children
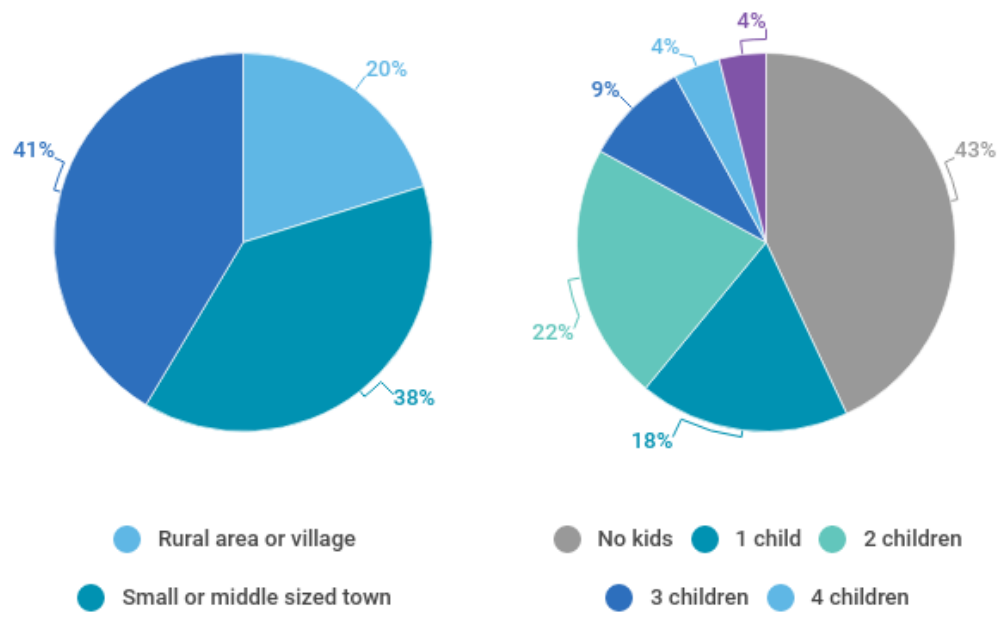

City or large town
3 children
4 children

5 children or more

\section{Employment Status}

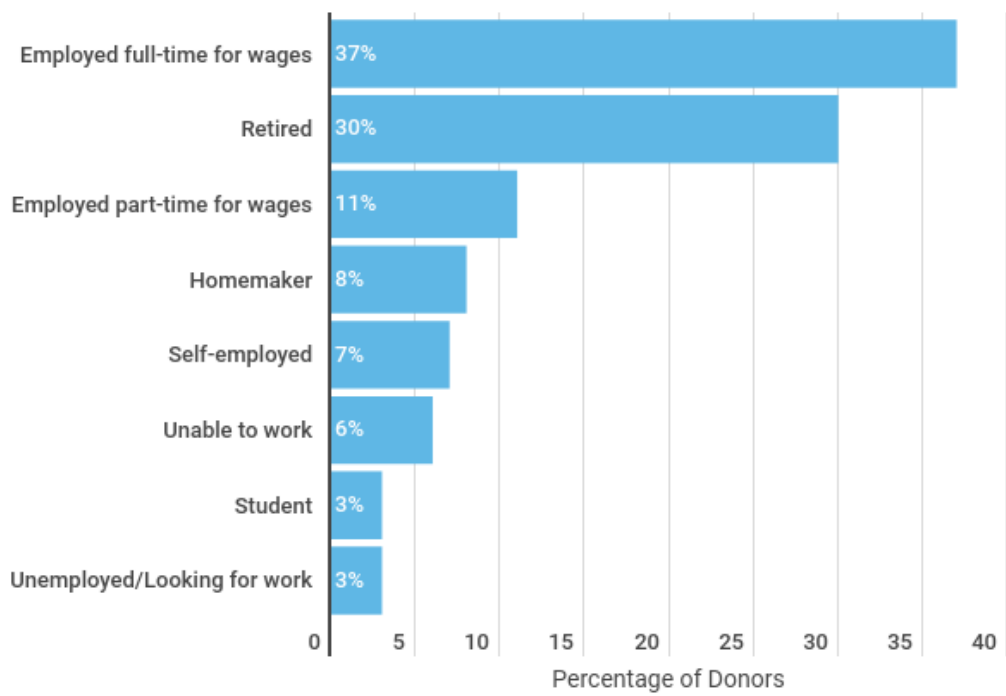

Note. The total for Region does not add up to $100 \%$ due to rounding, and for Employment Status because respondents were able to select more than one option. 


\section{Donor Activities And Habits}

This section includes data about many aspects of the lives of animal-cause donors.

\section{Volunteering And Working With Animals}

We asked respondents about their work and volunteering. As Figure 2 shows, about one in four people who donates to an animal cause also volunteers or works with animals or in an animalrelated field. Volunteering was much more common than paid work.

\section{Figure 2. Donors Working Or Volunteering In Animal-Related Fields}

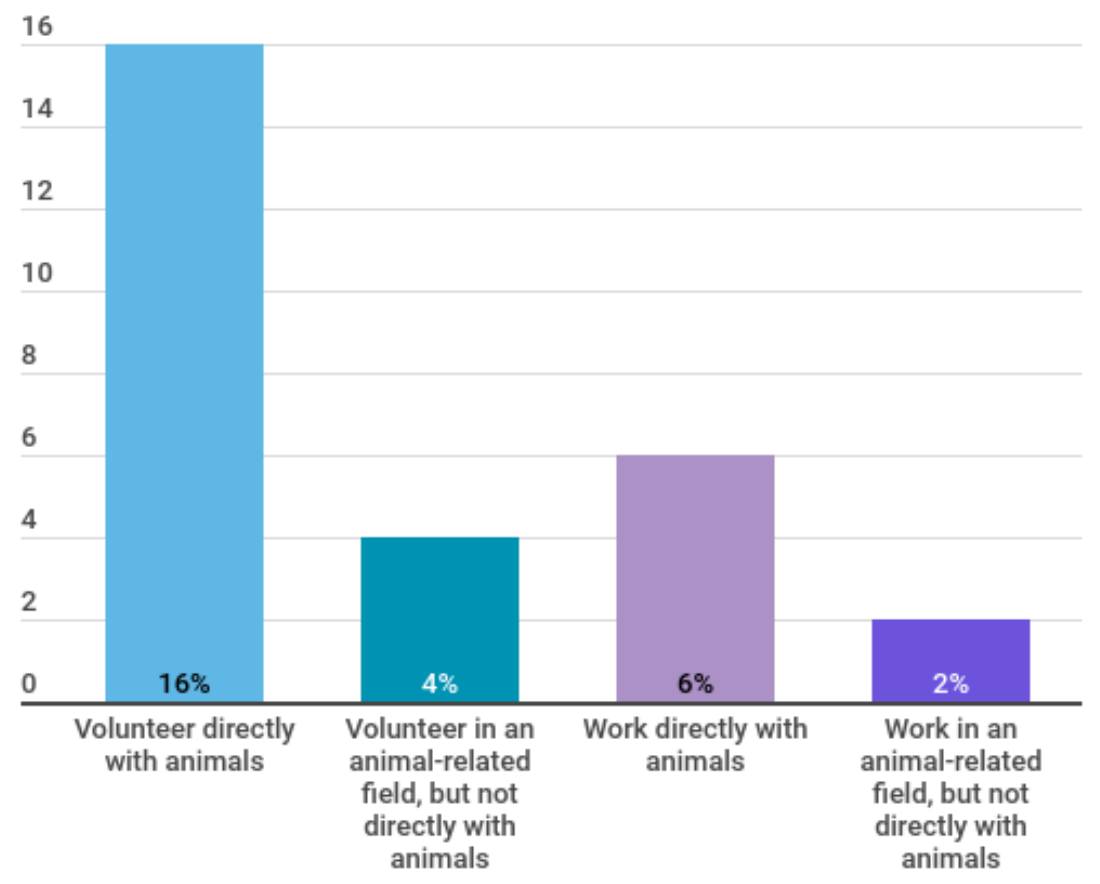

Notes. Respondents were able to select more than one option.

$75 \%$ of respondents do not work or volunteer in an animal-related field.

\section{Volunteers}

Of the respondents who volunteer with animals or in an animal-related field $(n=202)$, a large majority (89\%) work with animals regarded as pets, as shown in Table 4 (p. 14). This could be because they prefer companion animals or because most volunteer opportunities may come from shelters and rescues. 
Table 4. Volunteerism By Type Of Animal

\begin{tabular}{l|r|r|} 
& $\begin{array}{r}\% \text { of } \\
\text { Volunteers }\end{array}$ & $\begin{array}{r}\text { Margin of } \\
\text { Error }\end{array}$ \\
\hline Animals regarded as pets (e.g., cats, dogs, birds) & 89 & $+/-4 \%$ \\
\hline Wild animals (e.g., raccoons, birds, feral cats) & 16 & $+/-5 \%$ \\
\hline $\begin{array}{l}\text { Farmed animals/animals used for food (e.g., cows, pigs, chickens, } \\
\text { fish) }\end{array}$ & 14 & $+/-5 \%$ \\
\hline $\begin{array}{l}\text { Animals used for work or entertainment (e.g., horses, service dogs, } \\
\text { zoo animals) }\end{array}$ & 14 & $+/-5 \%$ \\
\hline $\begin{array}{l}\text { Animals used in research (e.g., lab rats, dogs, rabbits) } \\
\text { Other }\end{array}$ & 13 & $+/-5 \%$ \\
\hline
\end{tabular}

Note. Respondents were able to select more than one type of animal. The margin of error (confidence interval) shows how accurate each estimate will be to the population, 19 times out of 20 . The margin of error is provided for this analysis because of the smaller sample size $(n=202)$.

Respondents who volunteer were asked, in open-ended format, about the type of volunteering they do. Table 5 shows the coded responses (unweighted). Most volunteers work in shelters or rescues.

Table 5. Type Of Volunteering

$\%$ of Volunteers

\section{Animal shelters and rescues*}

Zoo

Veterinary care

Advocacy groups, non-profits

Sanctuary

Wildlife

Note. The figures in this table are percentages of the subset of respondents who volunteer with animals or in an animal-related field $(n=202)$. Some responses were coded in multiple categories. Responses that were too ambiguous to classify were excluded (about $3 \%$ of total). 


\section{faunalytics}

\section{Paid Professionals}

The number of respondents involved in paid work related to animals was quite low $(n=83)$. As shown in Table 6, the majority work with animals regarded as pets. However, working with other types of animals was more common than volunteering with them, as shown above.

Table 6. Work By Type Of Animal

\begin{tabular}{l|r|r|} 
& \multicolumn{1}{c}{$\begin{array}{c}\% \text { of } \\
\text { Professionals }\end{array}$} & $\begin{array}{r}\text { Margin of } \\
\text { Error }\end{array}$ \\
\hline Animals regarded as pets (e.g., cats, dogs, birds) & 70 & $+/-10 \%$ \\
\hline $\begin{array}{l}\text { Animals used for work or entertainment (e.g., horses, service } \\
\text { dogs, zoo animals) }\end{array}$ & 24 & $+/-9 \%$ \\
\hline \begin{tabular}{l|c|} 
Wild animals (e.g., raccoons, birds, feral cats) \\
Animals used for food (e.g., cows, pigs, chickens, fish)
\end{tabular} & 24 & $+/-9 \%$ \\
\hline Animals used in research (e.g., lab rats, dogs, rabbits) & 16 & $+/-8 \%$ \\
\hline Other & 6 & $+/-7 \%$ \\
\hline
\end{tabular}

Note. Respondents were able to select more than one type of animal. The margin of error (confidence interval) shows how accurate each estimate will be to the population, 19 times out of 20 . The margin of error is provided for this analysis because of the small sample size $(n=83)$.

We have not provided a table showing the type of work as we did for the type of volunteering because many people answered the question incorrectly or unclearly. Qualitatively, the most common types of work involved veterinary care, companion animal care, and animal charity work.

\section{Associations Between Volunteering/Working With Animals And Donating}

Donors who volunteer or work in animal-related fields were asked whether they also donate money to the organizations where they volunteer or work. As shown in Figure 3 (p.16), while most volunteers also donate, most paid professionals do not, in part because it is less often an option for them.

Notably, a follow-up question for volunteers who also donate revealed that the proportion of people who volunteered first, then started donating (38\%) was almost identical to the proportion who donated first, then started volunteering (39\%). The remainder said they started doing both around the same time $(18 \%)$ or that they didn't remember $(6 \%)$. 
Figure 3. Donating To The Organization Where You Volunteer Or Work

Do you donate to organization where you...
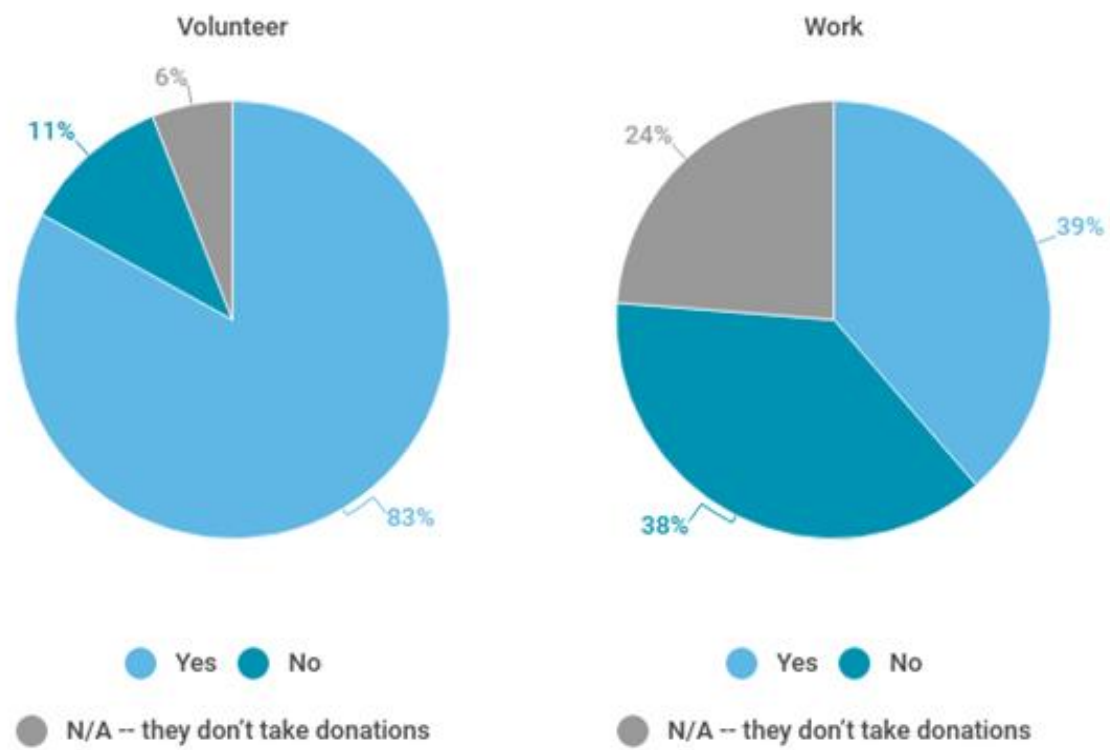

Note. These percentages include only the respondents who volunteer $(n=202)$ or work $(n=83)$ with animals or in an animal-related field. The totals do not necessarily add up to $100 \%$ due to rounding.

The margins of error for the volunteer estimates are $4-5 \%$, and for the work estimates are $10-11 \%$.

\section{Diet}

Approximately $5.7 \%$ of respondents in this study were vegan or vegetarian $\left(\right.$ veg $\left.^{*} n\right)$, with a margin of error of $+/-1.4 \%$. This was determined by their responses to the diet questions in Figure 4 below (p. 17).

Even the lower end of that range of values (4.3\%) places this estimate higher than most recent consumption-based estimates of veg ${ }^{*}$ nism in the U.S. population. Šimčikas \& Burdon estimated at most $1.4 \%$ veg$^{*}$ ns from the NHANES 2013-2014 data; Faunalytics found $2 \%$ in 2014; the Vegetarian Resource Group estimated 3.3\% veg*ns in 2016; Asher estimated $1.1 \%$ veg $^{*}$ ns in 2016; and Faunalytics studies from 2018 found $\underline{4 \%}$ and $2.2 \%$ veg*ns.

In short, it is likely that the rate of veg*nism among people who donate to animal causes is higher than in the general population. 


\section{Allthananyitices}

Figure 4. Diet

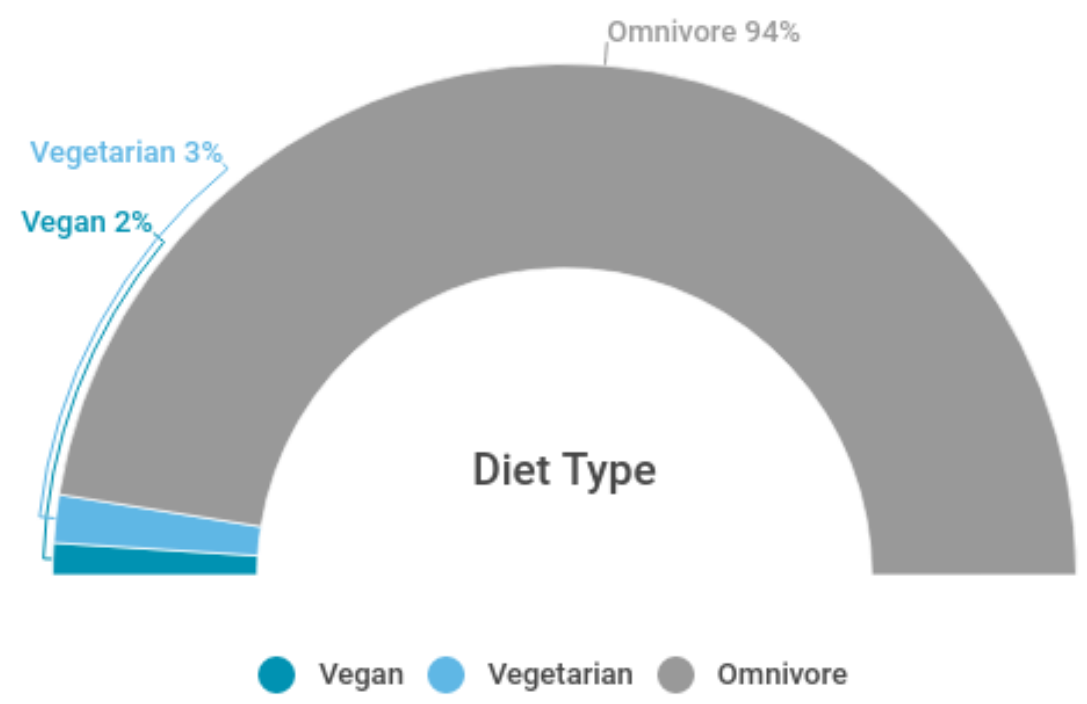

Note. The total does not add up to $100 \%$ due to rounding.

The question on the survey asked "Which of the following do you eat at least occasionally (including in other dishes or baked goods)?" The percentages of people who selected each product option are shown in Table 7.

\section{Table 7. Consumption Of Individual Products}

\begin{tabular}{|l|r|}
\hline & \% of Donors \\
\hline Dairy (cheese, milk, yogurt, etc.) & 89 \\
\hline Eggs (omelet, in salad, baked goods, etc.) & 88 \\
\hline Chicken (fried chicken, in soup, grilled chicken, etc.) & 86 \\
\hline Beef (steak, meatballs, in tacos, etc.) & 80 \\
\hline Fish and Seafood (tuna, shrimp, crab, etc.) & 75 \\
\hline Turkey (turkey dinner, turkey sandwich, in soup, etc.) & 74 \\
\hline Pork (ham, pork chops, ribs, etc.) & 70 \\
\hline Animal product alternatives (bean burgers, nut-based cheese, soy meatballs, etc.) & 29 \\
\hline Other Meat (duck, lamb, venison, etc.) & 26 \\
\hline
\end{tabular}




\section{faunalytics}

\section{Companion Animals}

Respondents were also asked whether anyone in their household currently has a pet or companion animal. As shown in Table 8, almost two thirds of respondents live with dogs. About half live with cats, and smaller percentages live with other animals.

According to the 2018 Simmons National Consumer Survey, approximately $38 \%$ of U.S. households have dogs and $25 \%$ have cats. People who donate to animal causes are clearly much more likely to live with cats and dogs than the general population.

Also, the proportion of donors in this study who had no companion animal in the home (14\%) was much lower than the proportion of U.S. households with no companion animal (32\%).

\section{Table 8. Companion Animals/Pets In Household}

$\%$ of Donors

\begin{tabular}{l|c}
\hline Dog(s) & 63 \\
\hline Cat(s) & 52 \\
\hline Fish & 10 \\
\hline Reptile(s) or amphibian(s): Snake, lizard, frog, toad, etc. & 6 \\
\hline Bird(s) & 6 \\
\hline Small mammal(s): Rabbit, mouse, guinea pig, ferret, etc. & 6 \\
\hline Horse(s), pony/ponies, or donkey(s) & 3 \\
\hline Other* & 2 \\
\hline No pets in household & 14
\end{tabular}

*Two thirds of 'Other' responses $(n=12$ of 18$)$ reported animals in the household that are typically farmed animals (e.g., pigs, chickens).

\section{Animal-Related Hobbies}

Respondents were asked if they regularly take part in any animal-related hobbies or activities. The options are shown in Table 9 (p. 19). As the table shows, slightly more than half of animalcause donors participate in a hobby or activity related to animals.

The most common responses included observational activities-bird-watching and animal photography—but also one destructive activity: fishing. Approximately 49.1 million people in the U.S. (15\% of the population) participated in fishing activities in 2017.

Compared to $23 \%$ of our respondents who said they fish regularly, this suggests that fishing is more common among people who donate to animal causes than the general population. In contrast, the number of respondents who engage in hunting is about the same as the general population ( $\underline{5 \%})$. 
Table 9. Animal-Related Hobbies And Activities

\begin{tabular}{l|r}
\hline \multicolumn{2}{|c|}{$\%$ of Donors } \\
\hline Bird-watching & 26 \\
\hline Fishing & 23 \\
\hline Animal photography & 21 \\
\hline Horseback riding & 9 \\
\hline Whale-watching & 6 \\
\hline Snorkeling or ScuBA diving & 5 \\
\hline Hunting or trapping animals (of any sort) & 5 \\
\hline Insect collection & 2 \\
\hline Other animal-related hobby/activity` & 6 \\
\hline None of the above & 47 \\
\hline
\end{tabular}

*53 respondents reported other activities. Most of them referred to pet care/pet-sitting activities (walking or training dogs, petting cats, etc., $n=28$ ). Ten referred to communing with wildlife (e.g., feeding) and seven mentioned volunteer activities like rescue/foster/shelter support.

\section{PART TWO: DONOR BEHAVIOR}

\section{Donation Amounts}

Respondents were asked how much they had given in total over the last twelve months to all animal charities, as shown in Figure 5. In addition, they were asked how much money they had given to all charities, which we used to calculate the percentage of their donations that went to animal causes.

The typical (median) donor gave $\$ 100$ to animal charities in the past twelve months. This made up $\mathbf{3 0} \%$ of their total donations. Respondents' donations to animal charities ranged from $\$ 1$ to $\$ 10,000$, and from less than $1 \%$ to $100 \%$ of their total donations. A more detailed breakdown is provided in Figure 5 below (p. 20).

As shown in the figure, two thirds (63\%) of donors gave $\$ 100$ or less to animal causes. All of these small donors account for only $13 \%$ of the total dollars that went to animal causes. On the other hand, a small handful of major donors who gave over $\$ 1000$ each (6\% of respondents) made up almost half of the total dollars that went to animal causes ( $47 \%$ of total donations).

This finding points to the disproportionate impact a few major donors can have on charitable organizations with small shifts in their donation preferences. At the same time, it is important not to overlook the power of many small donors-for instance, both of Obama's presidential campaigns were driven by grassroots support and small donations to a much greater extent than is usual. 
Figure 5. Total Donations To Animal Charities In Past 12 Months

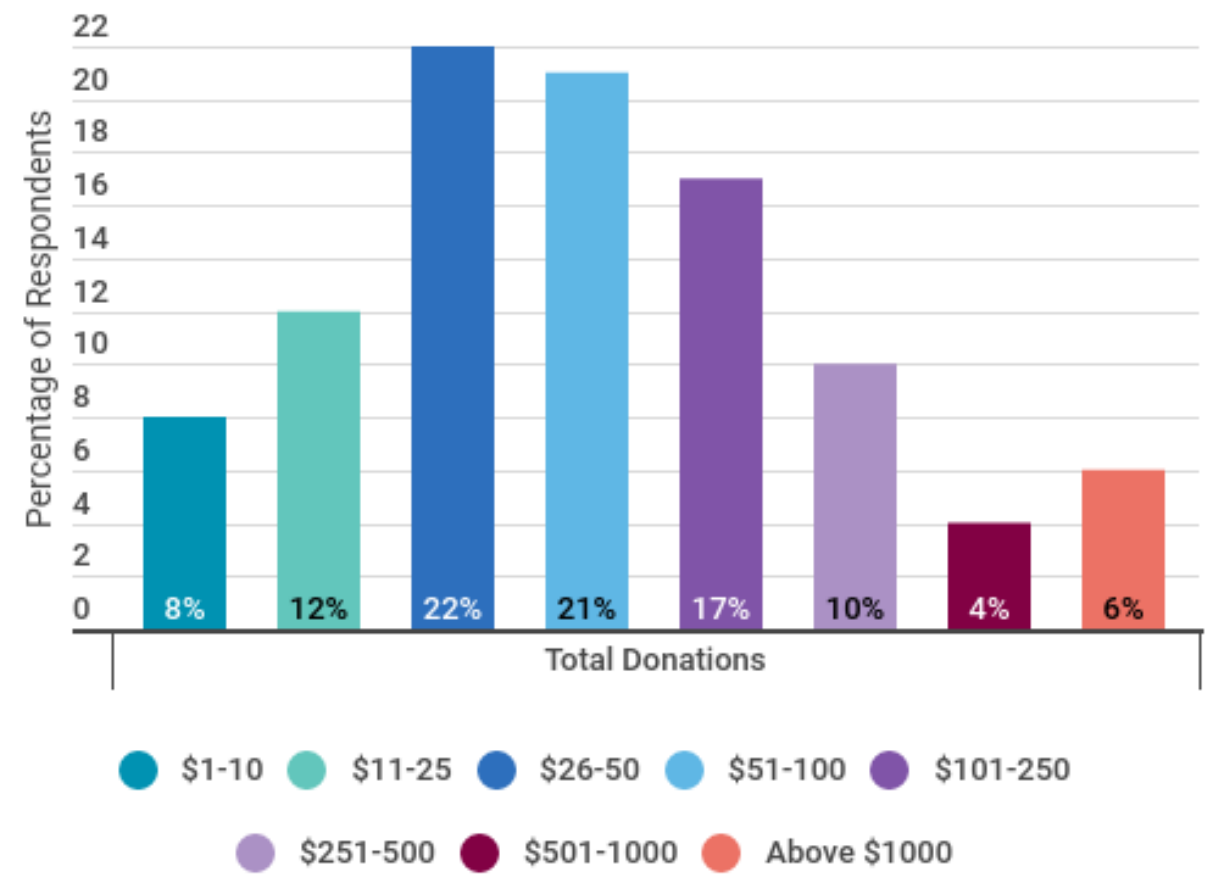

As noted above, donations to animal causes made up $30 \%$ of respondents' total donations. This indicates that the remaining $70 \%$ was divided between all human causes. From these data, we can't tell how exactly the amount of money given to animals compares to any individual human cause.

\section{Recurring Donations}

Respondents were also asked whether they had a recurring donation set up with any animal charity. As shown in Figure 6 below, approximately 1 in 10 donors to animal causes have recurring donations set up.

Figure 6. Recurring Donation To Any Animal Charity

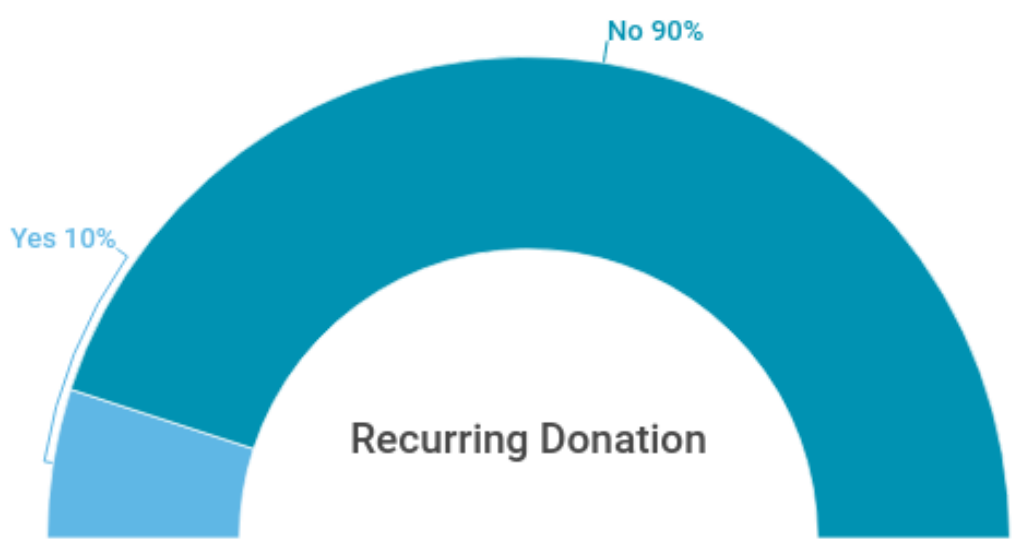




\section{Number Of Individual Charities Supported}

Respondents were also asked to estimate the total number of individual charities to which they had donated money in the past twelve months. They gave the total number of charities as well as the total number of animal charities.

As shown in Figure 7, which includes donations to all types of charities (i.e., not just animals), most people give to more than one charitable organization. The median number is 4 .

Figure 7. Number Of Charities (All Causes) Donated To In The Past 12 Months

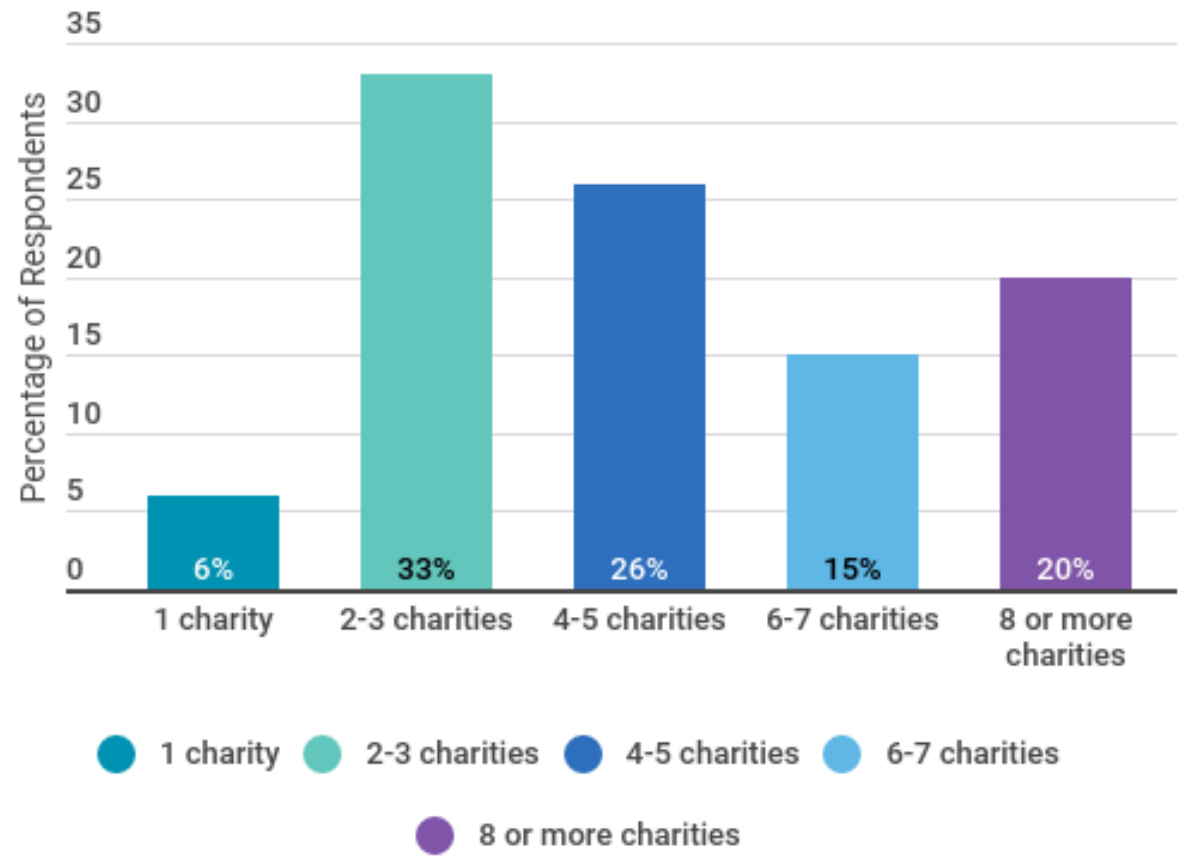

Next, Figure 8 (p. 22) shows how many individual animal charities people support. Donating to only one animal charity was common. About half of respondents $(51 \%)$ gave to only one animal charity (so the median number is one). The other half gave to two or more animal charities. 
Figure 8. Number Of Charities (Animal Causes) Donated To In The Past Twelve Months

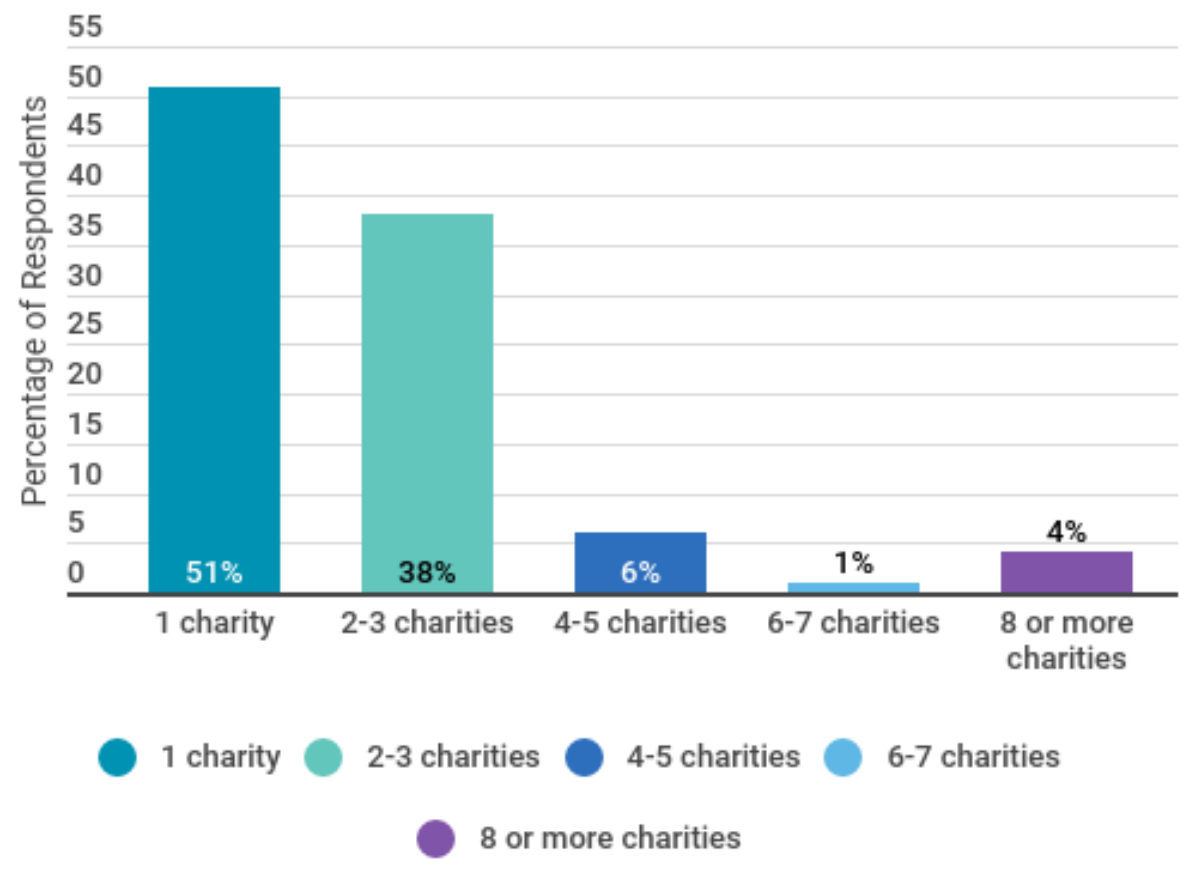

\section{Causes Supported}

\section{Other Causes Supported by Animal-Cause Donors}

The vast majority of donors (all of whom had donated to animal causes, as a requirement for the study) had also given money to at least one other cause. Figure 9 (p. 23) shows the other causes supported by animal-cause donors in the past twelve months. Only $9 \%$ said that they had donated solely to animal causes.

The most supported human causes were local social service organizations, children's charities, and emergency relief efforts. Only $32 \%$ had supported places of worship-quite low compared to $50 \%$ of donors from the general population who donate to religious causes.

Methodological note: That previous study estimated that $42 \%$ of animal-cause donors gave money to religious causes, but the current estimate of $32 \%$ is much more likely to be accurate because our sample of animal-cause donors is more than four times as large.

The results suggest that people who give to animal causes tend to prefer human causes for the vulnerable or needy (e.g., homeless people, children, victims of disaster) over those for interest groups or religious causes. Speculatively, highlighting animals' vulnerability to human exploitation and abuse could increase the size or frequency of donations from existing donors. 
Figure 9. Other Causes Supported By Animal-Cause Donors

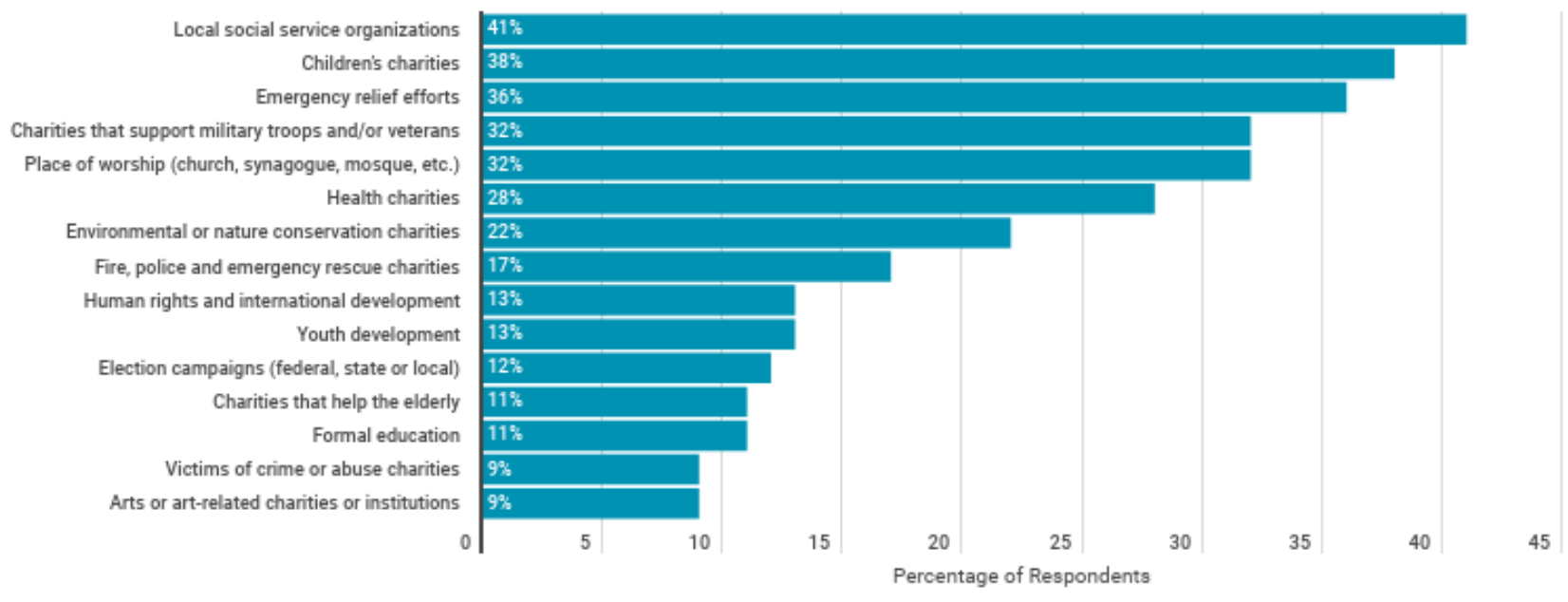

Note. Response options are paraphrased for length. See survey instrument for original text.

\section{Specific Animal Causes Supported}

Respondents were also asked to indicate the specific types of animal causes that they had supported, as shown in Figure 10 below.

\section{Figure 10. Types Of Animal Charities Donated To In The Past Twelve Months}

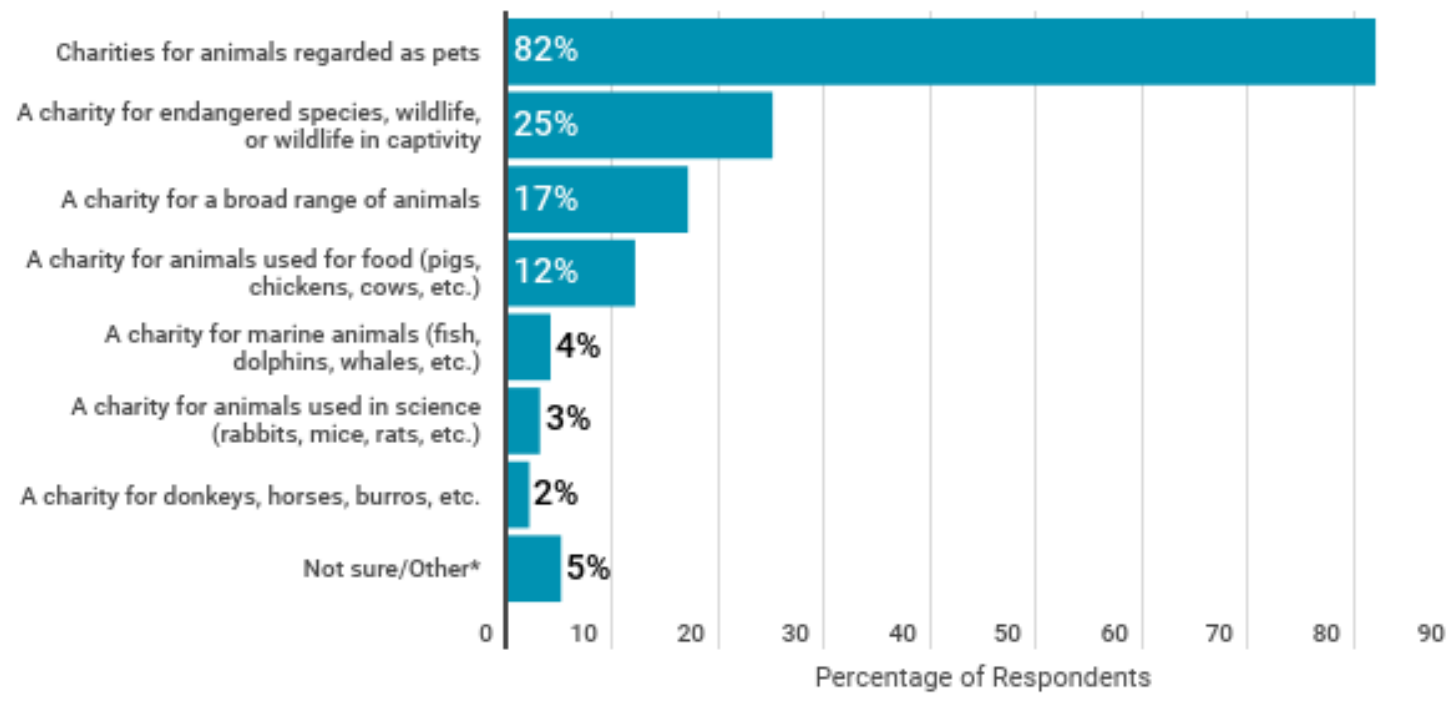

${ }^{*}$ Charities listed as "Not sure/Other" $(n=44)$ included local rescue groups, charities with a narrow target (e.g., old dogs or specific breeds, emergency rescue) and other minor organizations that are hard to classify. 


\section{faunalytics}

As is clear in the figure, companion animal causes ("charities for animals regarded as pets") received the vast majority of support. Breaking down that cause area further:

- $56 \%$ of all respondents had donated to a local animal shelter, humane society, or the Society for the Prevention of Cruelty to Animals

- $24 \%$ had donated to the American Society for the Prevention of Cruelty to Animals (ASPCA)

- $18 \%$ had donated to the Humane Society of the United States (HSUS)

- $16 \%$ had donated to a local charity focused on pets other than a shelter

- $6 \%$ had donated to a national or international charity focused on pets other than HSUS or ASPCA

Breaking down donations to charities for endangered species, wildlife, or wildlife in captivity:

- $\quad 23 \%$ of all respondents had donated to a charity focused on wildlife or endangered species conservation/rescue/rehabilitation (e.g., World Wildlife Fund)

- $6 \%$ of respondents had donated to a charity focused on wildlife in captivity (e.g., Performing Animal Welfare Society)

And finally, breaking down donations to charities for animals used for food:

- $7 \%$ of all respondents had donated to a farm animal sanctuary

- $6 \%$ of respondents had donated to other charities focused on animals used for food (e.g., Mercy for Animals, Compassion Over Killing)

\section{Do Companion Animal Donors Support Other Causes?}

Of donors who supported companion animal charities, $66 \%$ did not give money to any other type of animal charity. However, $20 \%$ of people who donated to companion animal charities also supported charities for endangered species, wildlife, or wildlife in captivity; $13 \%$ supported charities for a broad range of animals; and 10\% supported farmed animals. The other types of charities were supported by less than $5 \%$ of people who also donated to companion animal charities.

\section{Specific Animal Causes Supported When "All Else Is Equal”}

Past behavior is a better indicator of future behavior than what people say they will do. So the fact that the vast majority of respondents had donated to companion animal charities should be taken seriously. However, this does not mean that this trend is inevitable, because it doesn't tell us anything about why this is the case.

Is it just that people prefer companion animals over farmed animals, wildlife, marine animals, and so on? Past behavior can't tell us that because there are so many other factors at play. Most notably, companion animals-and charities for them-are everywhere. They are far more visible and familiar than most other kinds of animal charities, so people may simply be reminded to donate to companion animal charities more often, or they may know how to donate to them more easily. 
If all animal-related charities got equal billing - and it was equally easy to donate to any of them - would the pattern be the same, or would some of the underrepresented causes receive more donations?

To answer this question, we asked respondents to imagine that they had $\$ 100$ to donate to animal causes, and asked them how they would divide it up. We provided them with a list of broad categories by type of animal helped.

Figure 11 shows how much, on average, people believed they would donate to different animal causes when presented with all the options equally in our hypothetical donation scenario.

Figure 12 (p. 26) shows the percentage of people who donated to each type of animal cause in the hypothetical donation scenario.

Figure 11. Amount Donated By Animal Cause In A Hypothetical Exercise

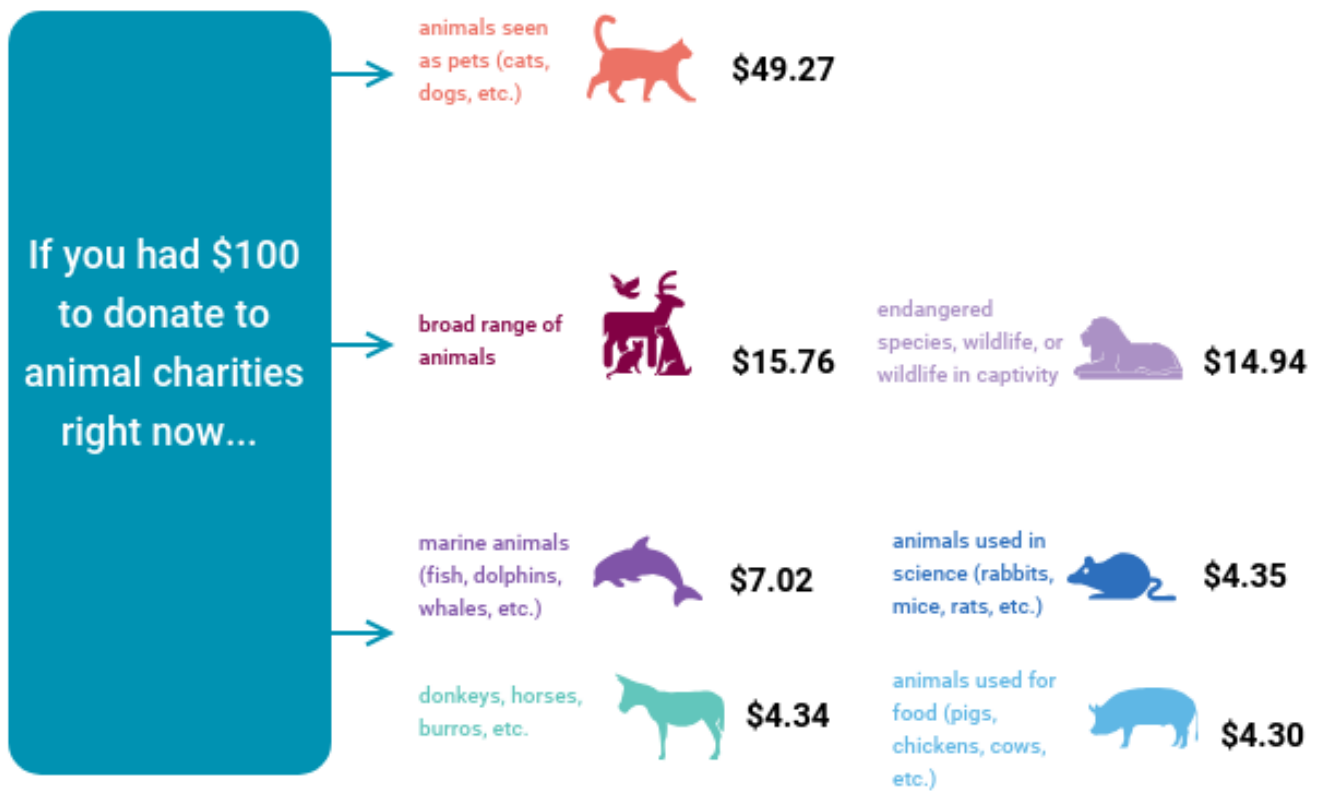




\section{Figure 12. People Who Donated To Each Cause In A Hypothetical Exercise}

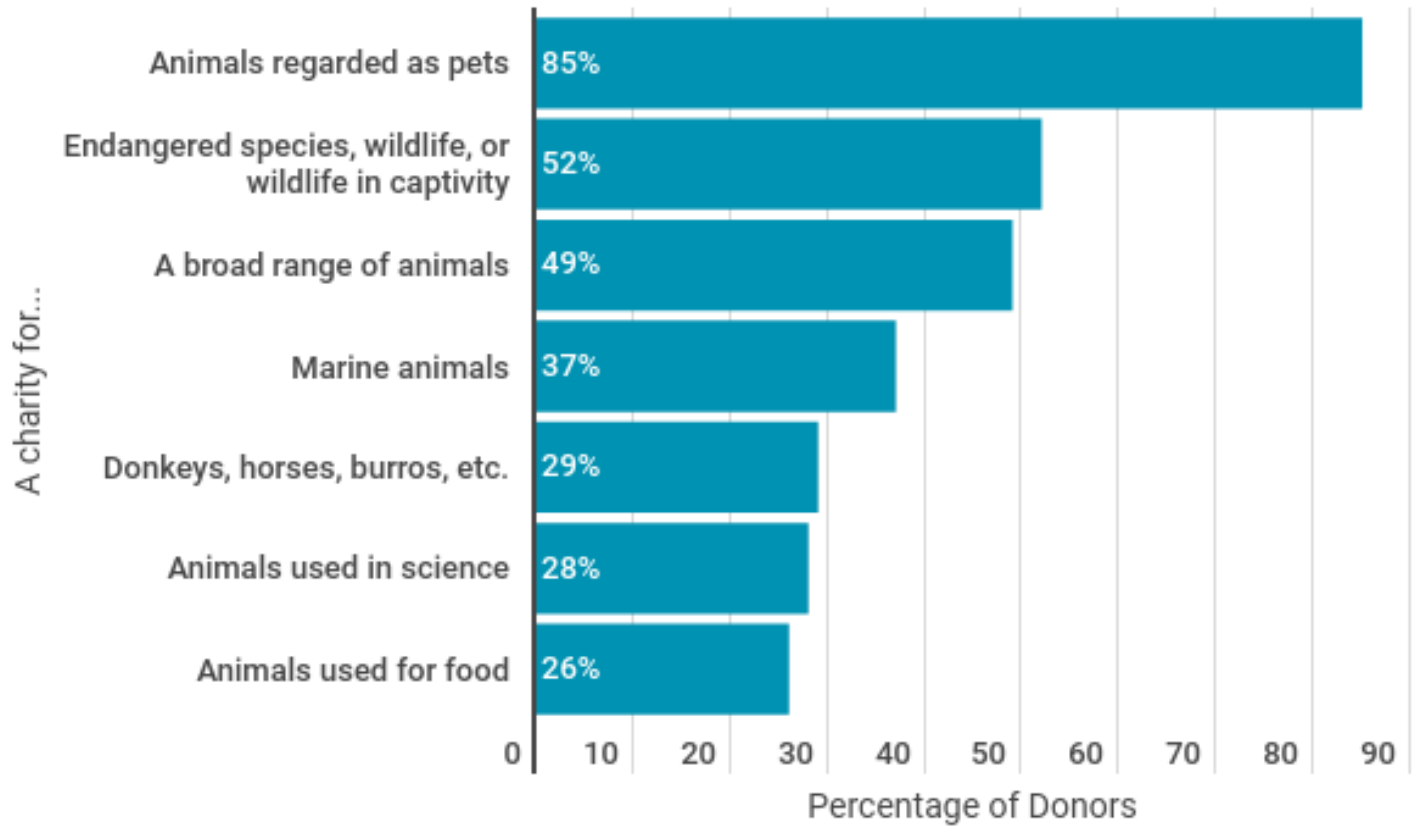

Note. Response options are paraphrased for length. See survey instrument for original text.

When presented with a range of charity options in a hypothetical donation scenario, the percentage of people who donated to companion animal charities was about the same as the percentage who had donated to them in "real life": $85 \%$.

However, the number of people who donated to all other animal causes increased dramatically from what we saw in Figure 10. When presented with the option to expand their donations, many people took it. This result suggests that the proportion of donations to non-companion animals can be partially explained by lack of visibility rather than lack of motivation.

Methodological note: Asking people to imagine making a donation has its own limitations, and this would benefit from a replication with real money. Consider the following points:

- A common issue with hypothetical questions is that people tend to over-estimate how much money they would donate, but because they had a fixed sum of $\$ 100$ to divide up in this question, that concern does not apply.

- Social desirability may have influenced the results if respondents felt pressured to choose more than one charity. We tried to avoid that scenario by asking "how would you choose to donate that \$100" rather than "divide that \$100." But this is still a valid concern.

- Because hypothetical donations have no real impact, people may be lazier than they would be with real money. However, we suspect that laziness did not play a large role here because it would have been much easier and faster for people to assign their $\$ 100$ to just one cause than to divide it among several causes. That was not the pattern we observed. 


\section{Most Important Charity}

Respondents were asked which one charity is most important to them personally. It didn't have to be an animal charity, because we were interested in how many would choose to name an animal charity.

Overall, about a third (35\%) of respondents named an animal charity as the most important to them (and another $2 \%$ listed an environmental or nature conservation charity). The remainder listed human-focused charities. We go into more detail about their most important animal charities in the next section.

Figure 13. Most Important Charity (All Causes)

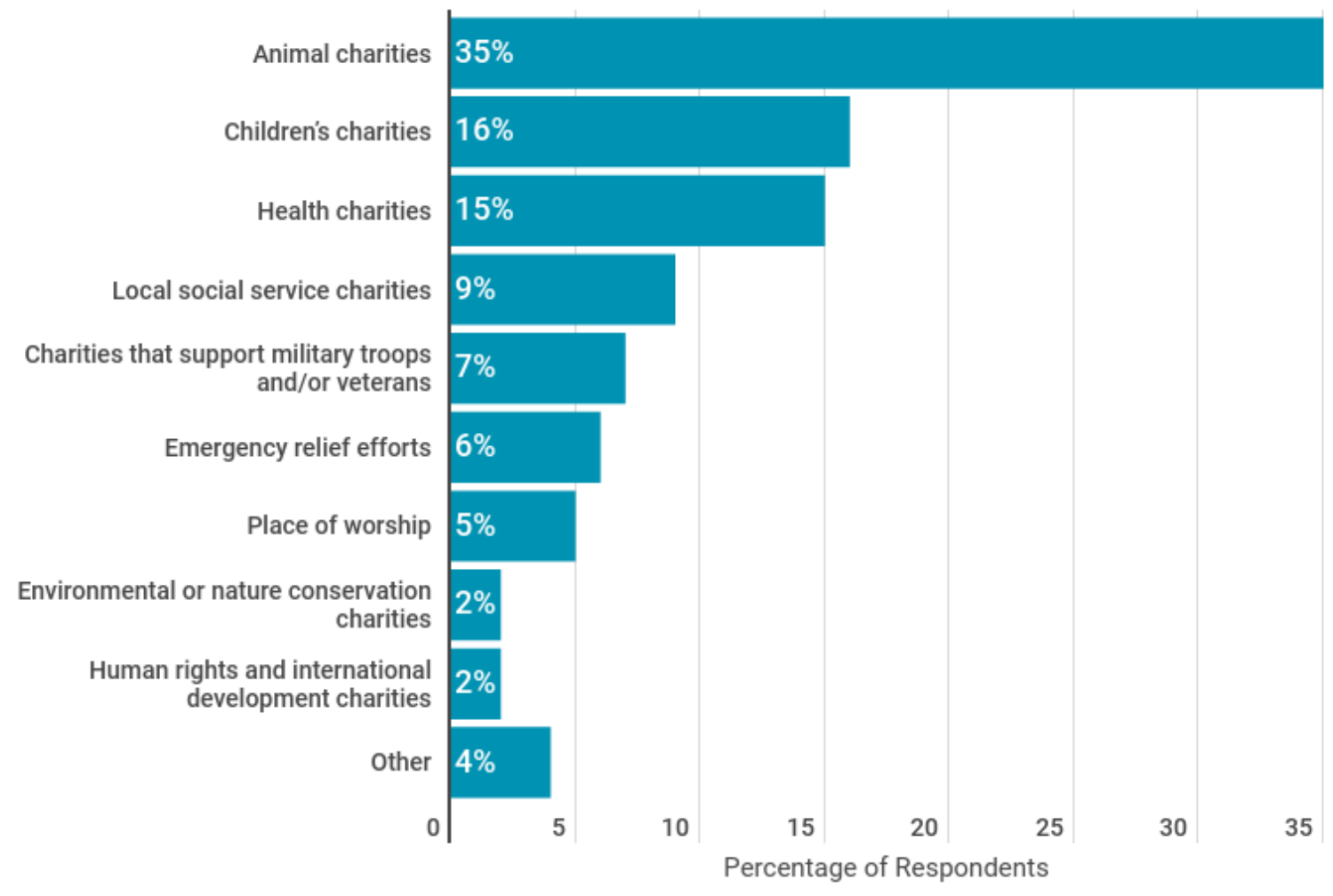

Note. 26 respondents did not name a specific charity or charity type in their 'Other' entry, so they were excluded from this analysis. An additional 25 respondents provided specific charity names, which were recoded into the correct categories. Response options are paraphrased for length. See survey instrument for original text.

Respondents were asked how much money they had given in the past twelve months to their most important charity. The median (middle) response was $\$ 100$, but ranged from $\$ 0$ to $\$ 25,000$.

Although most respondents had donated money to the charity they considered most important, a small number $(n=22)$ had not. When asked why, many cited personal financial reasons. Other reasons included having contributed in non-financial ways instead (donating goods, volunteering) and logistical reasons (only in-person donation possible, no reminders). 


\section{Most Important Animal Charity}

Respondents who did not name an animal charity as the most important to them were later asked which animal charity was most important to them. We combined the two questions to get a list of animal charities considered most important by respondents. These are presented in Figure 14 ( $p$. 28).

\section{Figure 14. Most Important Animal Charity}

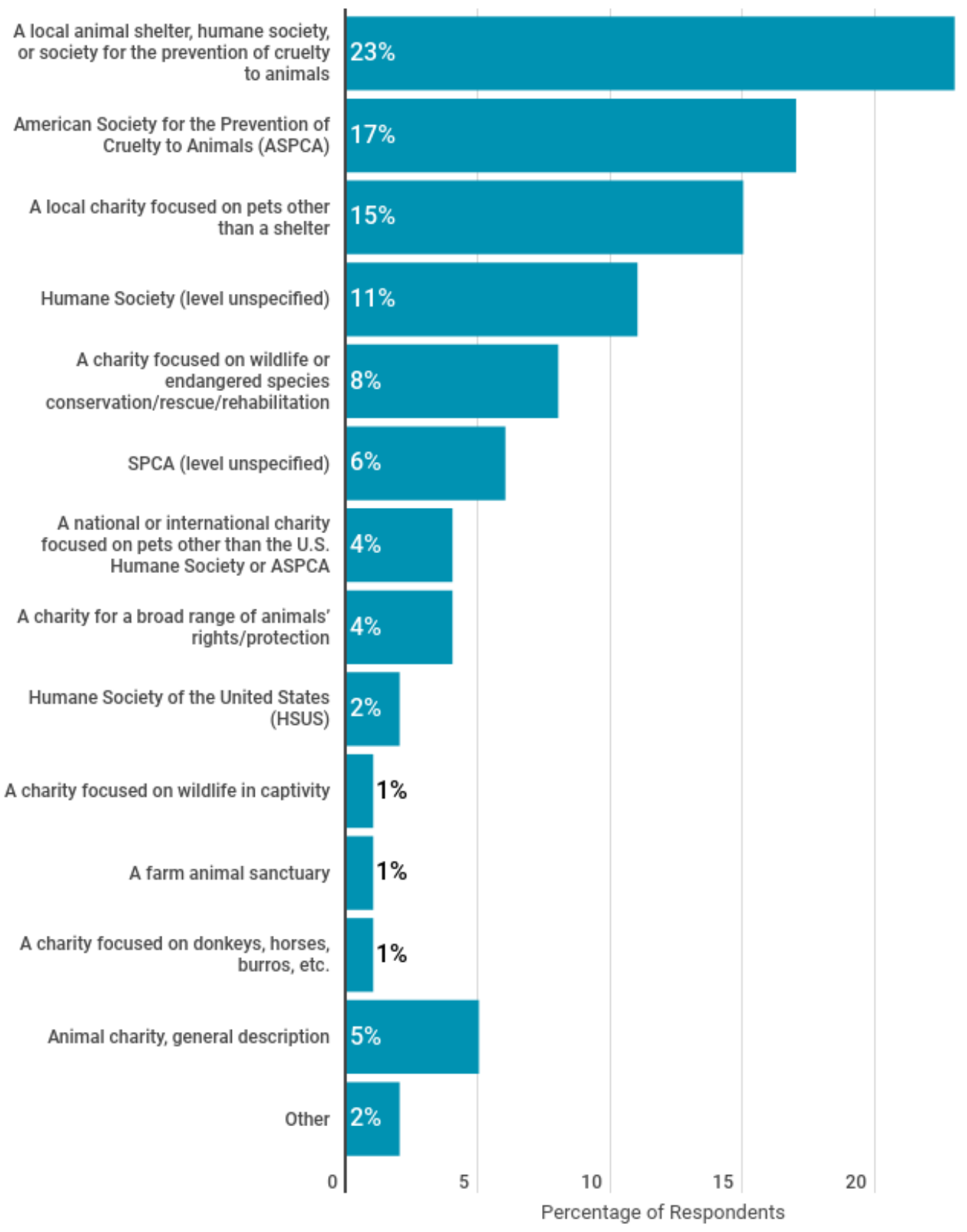

Note. This analysis excluded respondents who indicated that no animal charity was important to them $(n=67)$, who entered irrelevant/unclear responses $(n=28)$, or who did not provide an answer $(n=44)$. Charities with less than $1 \%$ are also excluded, namely those for: animals used for food (excluding farm sanctuaries), marine animals, and animals used in science. 


\section{Reasons For Donating}

Why do people donate to animal causes? We asked respondents exactly that. As shown in Table 10 below (p. 29; unweighted), the most common motivation was a general affection toward animals, with many people describing themselves as "animal lovers" (though it is important to bear in mind that the majority of respondents support companion animals).

Among other categories, we considered responses in terms of several common ways of describing our movement: Animal protection, animal welfare, and animal rights. People were much more likely to say that they were motivated by animal protection or welfare than animal rights. Describing animals as "vulnerable" or "innocent" was common, while describing them as deserving of equal treatment or respect was not.

Although only a small percentage of respondents volunteered this phrasing, it is interesting and concerning to note a tendency to describe caring for animals as a weakness. For instance, "having a soft spot for animals" or "I can't help it." We suspect that in a closed-ended question asking about this, many more people would describe caring for animals in these terms. It seems indicative of how Western society sees caring about animals-as a failing to be overcome.

Table 10. Reasons For Donating To Animal Causes

\begin{tabular}{|c|c|c|}
\hline Reason & Example & $\begin{array}{r}\% \text { or } \\
\text { Respondents }\end{array}$ \\
\hline Affection toward animals (general) & "Animal lover" & $31 \%$ \\
\hline Animals need protection & "Animals are at the mercy of humans" & $22 \%$ \\
\hline Animal welfare - negative focus & "Animals do not deserve cruelty" & $16 \%$ \\
\hline Animal welfare - positive focus & $\begin{array}{l}\text { "Because I care about the welfare of } \\
\text { animals" }\end{array}$ & $8 \%$ \\
\hline $\begin{array}{l}\text { Affection toward specific species/type } \\
\text { of animals }\end{array}$ & "Because I love cats \& dogs" & $8 \%$ \\
\hline $\begin{array}{l}\text { Direct experience/contact with animals } \\
\text { (pet owners, raised with animals, etc.) }\end{array}$ & $\begin{array}{l}\text { "I have five rescue cats and one rescue } \\
\text { dog" }\end{array}$ & $7 \%$ \\
\hline Desire to help/altruism (general) & "Because I care" & $4 \%$ \\
\hline Gratitude, reciprocity to animals & $\begin{array}{l}\text { "I think it's a good way to reciprocate for } \\
\text { all the love they give me" }\end{array}$ & $3 \%$ \\
\hline Nature/environmental conservation & $\begin{array}{l}\text { "Because I care about wildlife and its } \\
\text { protection" }\end{array}$ & $2 \%$ \\
\hline $\begin{array}{l}\text { Animals provide benefits to humans } \\
\text { (self or others) }\end{array}$ & "Animals...are therapeutic!" & $2 \%$ \\
\hline Animals have rights & $\begin{array}{l}\text { "Because I want to see animals well } \\
\text { taken care of and treated like everyone } \\
\text { else" }\end{array}$ & $2 \%$ \\
\hline Animal welfare (general) & "Am passionate about animal welfare" & $1 \%$ \\
\hline $\begin{array}{l}\text { Description of caring for animals as a } \\
\text { weakness }\end{array}$ & $\begin{array}{l}\text { "I have a soft spot in my heart for } \\
\text { animals" }\end{array}$ & $1 \%$ \\
\hline Religion & "Animals are God's creation" & $1 \%$ \\
\hline
\end{tabular}

Note. An additional $11 \%$ of respondents did not provide a reason, and $8 \%$ provided other reasons that did not fit into any of these categories. 


\section{faunalytics}

\section{Donation Methods}

Respondents were asked to select all methods by which they had made donations to animal charities in the past twelve months, as well as their preferred method of donation (where they were allowed to select up to three options). Both are shown in Figure 15 (p. 31).

As you can see from the light blue bars in Figure 15, online donations via a charity's website were the most commonly used, but not overwhelmingly so. Overall, $39 \%$ of donors had donated online (via the charity's website or social media). About a quarter of donors had donated by mail or in person, and more than $10 \%$ had used options at store checkout counters or had purchased merchandise from a charity.

Respondents' preferred donation methods (blue-green bars) are similar to the methods they had actually used, but there are several options that may be underused. For the methods with an asterisk before the text (indicating a significant difference), more people would like to use it than have used it. Increasing the availability of these options may increase donations.

Most notably, there is a 15\% gap between the proportion of donors who would like to donate on their bill at a store checkout (29\%) and those who have done so recently (14\%). More charities may wish to test the feasibility of this option, bearing in mind that it is likely to yield a large number of small donations (and possibly increase name recognition) rather than larger donations. 


\section{Illtranasy yites}

\section{Figure 15. Donation Methods Used And Donation Methods Preferred}

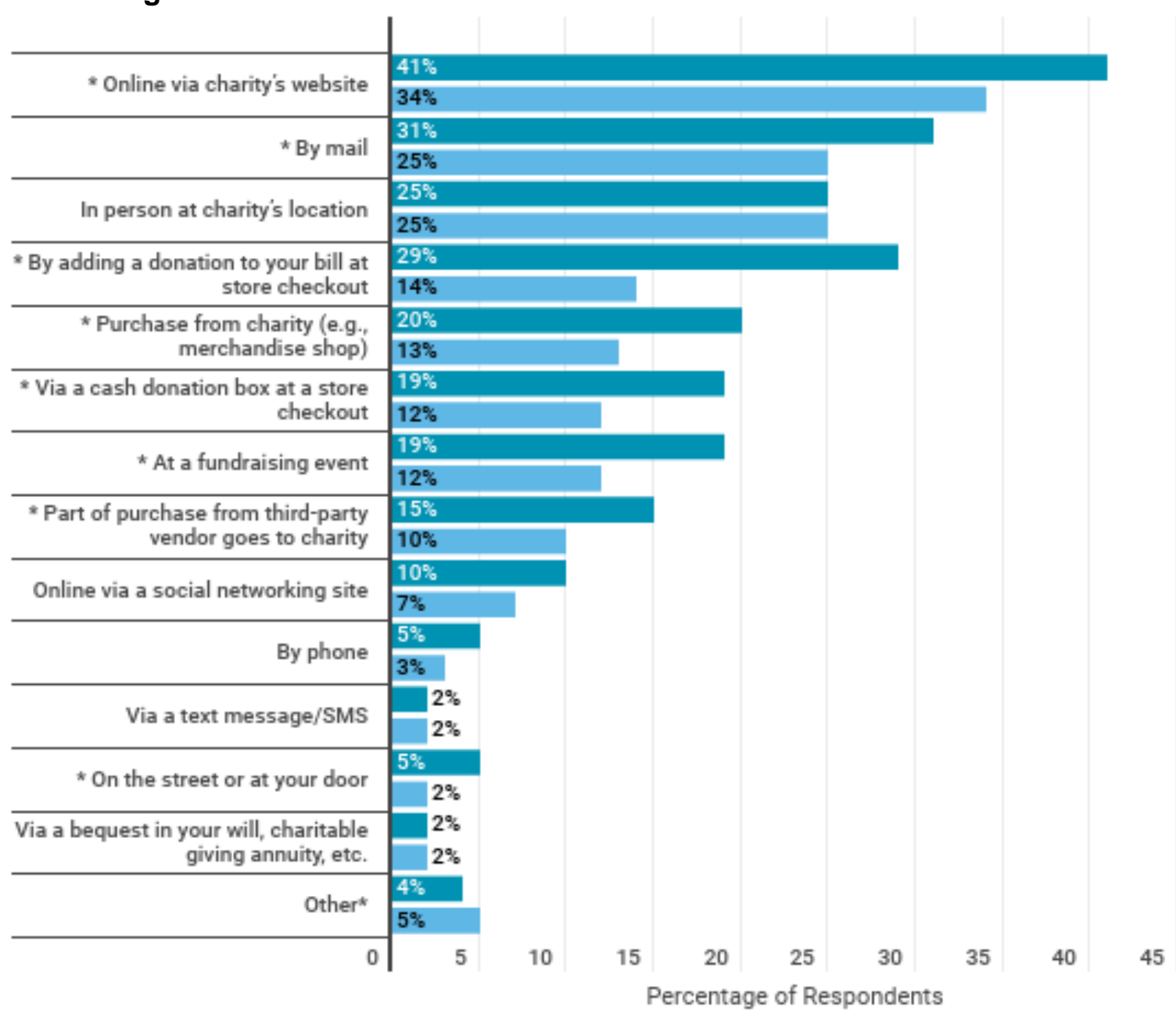

Methods Preferred $\bigcirc$ Methods Used

Note. Response options are paraphrased for length. See survey instrument for original text. *Of respondents who indicated "Other" preferences $(n=37)$, about a third mentioned automatized donation methods, such as payroll deductions or recurring donation. A few respondents also mentioned donating by check or other types of online donation, such as crowd-funding.

\section{Donation Methods By Specific Animal Cause}

We also did a quick comparison of people who donate to non-companion-animal causes versus people who donate to companion animals only. Their patterns of use and preferences differed, but not massively so. For instance, $41 \%$ of people who have donated to non-companion-animal causes have done so via a charity's website and $45 \%$ listed that method among their preferences. At the same time, $24 \%$ of people who have donated to non-companion-animal causes have donated by mail in the past twelve months and $26 \%$ listed mail among their preferences. 


\section{faunalytics}

\section{Other Methods Of Support}

Respondents were also asked to select all the non-financial ways in which they had supported animal charities in the past twelve months. Table 11 shows those other methods.

It might seem reasonable to expect that more people would have made low-effort contributions like signing a petition or promoting a charity online than high-effort, in-person ones like volunteering, attending an event, or donating goods. However, this was not the case. Donating goods was the most common means of providing non-financial support, and the number of respondents who volunteer is not significantly lower than the number of respondents who signed a petition or sent an email/letter.

Table 11. Support To Animal Charities In The Past Twelve Months

\begin{tabular}{l|r} 
& $\begin{array}{c}\% \text { of } \\
\text { Donors }\end{array}$ \\
\hline Donated goods or items & 41 \\
\hline Signed a petition, or sent an email or letter & 25 \\
\hline $\begin{array}{l}\text { Donated time/volunteered } \\
\text { Promoted a charity online (i.e., became a Fan on Facebook, tweeted about, forwarded } \\
\text { an email to friends, etc.) }\end{array}$ & 22 \\
\hline \begin{tabular}{l} 
Attended or volunteered at a fundraising event \\
\hline Participated or sponsored someone in a walk, run, or similar activity
\end{tabular} & 16 \\
\hline Attended or organized a march, protest, or demonstration & 3 \\
\hline Otherk & 3 \\
\hline None of the above & 3 \\
\hline
\end{tabular}

* The most notable "Other" forms of support included adoption, fostering, and rescue activities. 


\section{Conclusions \& Recommendations}

The results of this study cover a wide range of topics and all have applicability to increasing the capacity of animal protection work. Because we can't cover them all in depth, this section focuses on the findings tied to our strongest recommendations.

Animal advocates can increase funding to animal causes by persuading current donors to increase their donations, by persuading past donors to donate again, and by bringing in new donors. The first two categories represent the low-hanging fruit of fundraising. The best predictor of donating is having donated before. However, that last category-new donors-is potentially the most lucrative in the long run, because the pool is huge: $88 \%$ of the population. We have tried to keep all of these categories in mind as we frame our recommendations.

\section{Remind People Of All Animals In Need}

Companion animal charities get the vast majority of animal-cause funding. This study was no exception, showing that $82 \%$ of people had donated to companion animals in the past year. However, it also showed that some of this imbalance may actually be about familiarity rather than preference.

When presented with a range of charity options in a hypothetical donation scenario, the percentage of people who donated to companion animals was about the same (85\%), but the numbers who donated to other animal causes increased dramatically. This result suggests that the smaller proportion of donations to non-companion animal charities can be partially explained by their lack of visibility rather than donors' lack of motivation. When presented with the option to expand their donations, many people took it.

This result suggests that reminding people that a broad range of animals need their support-not just companion animals-may increase donations to underfunded charities. Bearing in mind that people will go to extreme lengths to justify their meat consumption, we suggest that soliciting donations for a broad range of animals-including farmed and companion animals simultaneously-may increase donations.

We suspect that, normally, it may be difficult for an omnivore to donate to causes for farmed or marine animals because they eat them. Even if they would like to contribute to welfare improvements, it means confronting the meat paradox head on: I like them, but I eat them. If a donation appeal includes many types of animal, the prospective donor can rationalize it more easily. (Psychology has shown, similarly, that people sometimes prefer to rationalize a donation; Holmes, Miller, \& Lerner, 2002).

Please note that this suggestion is based on our theories about the results of this study and is not yet supported by experimental evidence. However, we intend to look at this specific question in the near future to provide stronger recommendations.

\section{Identify Demographic Groups With The Most Potential}

Current donors to animal causes are older, more often female, more often White and nonHispanic, less often from the South, and higher-income than the general U.S. population. It is 


\section{faunalytics}

tempting to think that these are therefore the best demographics to target for new donations. However, simplistic demographic analyses can cause a self-fulfilling prophecy, in which the same groups are constantly targeted and therefore continue to emerge as the most common donors.

We improved on this analysis by looking at the proportion of people in each demographic group who had donated money in the past 12 months, but not to any animal cause. These individuals have the means to donate, but have not supported animals. Better donation appeals toward these groups have the potential to broaden our support.

This analysis identified people aged 55 and up of both genders (but especially men) and people with incomes of $\$ 50,000$ or more (but especially $\$ 100,000$ or more) as potential donors. These groups contain large proportions of individuals who could donate to animals but are not doing so currently. If campaigns could successfully appeal to one or more of these demographics, it could dramatically increase the number of donors to animal causes.

Note that several of the current donor groups (e.g., women, White people, non-Southerners) did not rise to the top of the potential donor list. This indicates the importance of considering more than just the current donor profile. Some of the frequent-donor demographics are more "tapped out" than others.

\section{Finding Donors In Interest Groups}

Perhaps unsurprisingly, there are more people with companion animals and more people who follow a vegan or vegetarian diet among animal-cause donors than the general population. Also, hobbies that involve observing and appreciating animals-including bird-watching and animal photography-are fairly common; about one in four animal-cause donors pursue these types of hobbies.

At the same time, animal-cause donors are more likely to fish regularly than the general population, despite the harm it does. From this study, we can't tell what is behind this correlation. It is possible that people who fish enjoy spending time in nature, and support animal causes from that perspective. They may also believe fish to be less intelligent or capable of feeling pain than other animals (Mercy For Animals, 2017). Although looking for donors among people who fish may be distasteful to many advocates, creating a connection with these individuals also provides later opportunities for education.

Targeting interest groups has the potential to expand our pool of typical donors. In particular, advocacy campaigns that focus on wild animals might be particularly appealing to people who enjoy bird-watching, whale-watching, snorkeling, or other outdoor activities (even fishing), especially if the campaign were to reference those activities. Organizations that support a range of animals have the option of focusing a campaign on particular species in order to raise funds for the benefit of all species.

\section{Think Outside The Online Box}

Less than $40 \%$ of respondents had donated money online in the past twelve months. Donating by mail, via cash box at a store checkout, or on a store bill ("Would you like to add $\$ 1$ for animals to your purchase today?") were among the options that respondents preferred. 


\section{faunalytics}

With the ease of setting up online donations these days, some charities may be not be considering other options. Particularly with animal donors being older than the general population, providing alternative donation methods may broaden your accessibility. Also bear in mind that respondents completed this survey online, meaning that they are all at least somewhat computer literate. If anything, the results likely underestimate the proportion of potential donors who would prefer to use old-fashioned methods.

We do not mean to imply that all charities should start using direct mail appeals, which are expensive, difficult, and potentially wasteful. Although it may be useful strategically in particular circumstances, this recommendation is aimed more at charities that have any in-person outreach at all. Whether it is tabling at a Veg Fest, leaflets at a protest, sanctuary visiting hours, or something else, consider how to include a convenient, barrier-free donation request. A cash box for loose change or a mailing address for checks are simple to implement and manage. And even incremental differences can add up.

\section{Ask For Non-Monetary Forms Of Support}

Many respondents had supported animal charities in other ways besides monetary donation. Donating goods or items was common, and a substantial number of respondents had donated their time by volunteering, signing petitions, or writing emails or letters.

These respondents include just those people who have also donated money, but it is possible to increase your base of support beyond donors by considering how to request and use these other options. Even organizations with less direct use for volunteer support or donations of goods should consider two additional benefits:

First, by making a small request, like signing a petition, you create a new relationship with a supporter. Every new relationship creates more opportunity for growth and even new donations down the road. The foot-in-the-door phenomenon is the tendency for people who agree to a small request to agree to larger requests later. Our data support this. We found that the vast majority of people who volunteer with an animal organization also donate to it. It was 50/50 whether they donated first or started volunteering first.

And second, as discussed above, under "Interpreting The Demographic Trends," making smaller and more varied requests may allow your organization to create relationships with new communities of supporters. Not everyone can afford to donate, and not everyone has time to volunteer, but increasing the number of ways people can support your organization increases the likelihood of creating new relationships. 


\section{-1) faunalytics}

\section{Supplementary Materials}

\section{Data-Cleaning Procedure}

The initial dataset downloaded from Qualtrics contained 10,652 cases. We first excluded 87 duplicate or blank responses, then 1,133 cases that were included as the result of a panel glitch (i.e., respondents who started the survey but were disconnected before even completing the screener). These cases were excluded immediately during data collection so they were not included in quota calculations at all. After this broad initial sweep of data cleaning, the dataset comprised 9,432 cases.

Next, we removed 133 respondents who were not part of the target population, leaving 9,299 cases. Of those removed at this stage, 129 respondents were under 18 years old and 22 respondents lived outside the U.S. There was overlap between those categories.

Per our pre-registered plan, attention checks were included in the screener portion of the survey to ensure that animal-cause donors were not more likely to be excluded than other respondents, which would have introduced bias. Respondents were excluded from the study (and from quota calculations to avoid bias) if they failed either of two attention checks:

- First, if they indicated that they had run a mile in less than two minutes (which is humanly impossible); or

- Second, if they gave inconsistent answers in back-to-back questions (saying that they had donated to a charity in the past twelve months and then that they hadn't).

In total, 287 respondents were removed for failing the first check and 160 for failing the second.

We were more cautious in excluding respondents from the sample who completed the full survey to avoid introducing bias (again, per our pre-registered plan). However, an additional 22 respondents were excluded from the analyses. Those excluded in this final stage of data cleaning were:

- Nine respondents who entered nonsense answers for the open-ended questions;

- Three who completed the survey in less than one-third of the median time; and

- Ten who, despite having said they had donated to an animal charity, later answered 0 to any of the following questions: number of organizations donated to in the past twelve months; number of animal organizations donated to in the past twelve months; total amount donated in the past twelve months; and total amount donated to animal charities in the past twelve months.

After all the steps in this data-cleaning procedure were complete, we were left with a full sample of 8,838 respondents and 1,036 who had donated to an animal cause in the past twelve months. 